\title{
VIGOR DE SEMENTE, EMERGÊNCIA E DESENVOLVIMENTO INICIAL DE ESPÉCIES DO ESTRATO HERBÁCEO E SUBARBUSTIVO DO CERRADO EM CONDIÇÃO DE VIVEIRO
}

Flaviana Delmiro Oliveira ${ }^{1}$, Guilherme Murilo de Oliveira $^{2}$, Carlos Eduardo Batista de Oliveira $^{3}$, Carlos de Melo Silva-Neto ${ }^{4}$, Fábio Venturoli ${ }^{5}$

1. Mestranda em Agronomia, Universidade Federal de Goiás, Goiânia, Brasil.

E-mail: flavianadelmiro@gmail.com

2. Agrônomo, Universidade Federal de Goiás, Goiânia, Brasil.

3. Engenheiro Florestal, Universidade Federal de Goiás, Goiânia, Brasil.

4. Doutorando em Agronomia, Universidade Federal de Goiás, Goiânia, Brasil.

5. Professor Doutor Adjunto II do Departamento de Engenharia Florestal,

Universidade Federal de Goiás, Goiânia, Brasil.

Recebido em: 08/09/2015 - Aprovado em: 14/11/2015 - Publicado em: 01/12/2015

DOI: http://dx.doi.org/10.18677/Enciclopedia_Biosfera_2015_168

\begin{abstract}
RESUMO
As espécies vegetais tendem a realizar ajustes morfológicos, fisiológicos e alterações no desenvolvimento. As alterações em relação diferentes condições de ambiente é uma resposta específica de cada espécie. Assim objetivou-se investigar, em condições de viveiro, a germinação e desenvolvimento de Senna alata, Clidemia hirta, Olyra latifolia e Psychotria trichophora do Cerrado. Foi realizado o experimento em viveiro, onde os diferentes recepientes com sementes foram expostas a pleno sol e sombreamento de $50 \%$. Cada tratamento foi constituído com cinco repetições de 25 plântulas de cada uma das quatro espécies estudadas, obtendo 2.000 mudas. O potencial de germinação foi estimado por meio do teste tetrazólio e emergência e crescimento das plântulas (altura, diâmetro do coleto e massa de matéria seca). 0 teste de tetrazólio mostrou-se eficaz na avaliação da viabilidade das sementes. As sementes de $C$. hirta e $P$. trichophora não germinaram indicando dormência. Já o recipiente saco plástico proporcionou um melhor desenvolvimento de Senna alata, sendo a mesma tolerante à incidência de luz direta, porém desenvolve-se melhor em ambiente de telado com $50 \%$ de luz.
\end{abstract}

PALAVRAS-CHAVE: Luminosidade, Produção de mudas, Sombreamento.

\section{VIGOR SEED, EMERGENCE AND EARLY DEVELOPMENT OF SPECIES OF HERBACEOUS AND SUBSHRUB CERRADO IN NURSERY CONDITION.}

\begin{abstract}
Plant species tend to make adjustments morphological, physiological and developmental changes. The changes to different environmental conditions is a specific response of each species. Thus aimed to investigate in greenhouse conditions, germination and early development of Senna alata, Clidemia hirta, Olyra latifolia e Psychotria trichophora in Cerrado. The experiment was conducted in greenhouse where the recipient system with different seeds were exposed to full
\end{abstract}


sunlight and shading of $50 \%$. Each treatment had five replicates of 25 seedlings of each of the four species studied, obtaining 2,000 seedlings. Checking the germination potential by the tetrazolium test and seedling emergence and development with height variables, stem diameter (DC) and dry matter (DM). The tetrazolium test was effective in assessing the viability of the seeds. The Clidemia seeds hirta and Psychotria trichophora did not germinate, indicating dormancy. The longer the plastic bag, provided a better development of Senna alata, with the same tolerant to strong direct light, but grows best in a greenhouse environment with $50 \%$ of light.

KEYWORDS: Luminosity, Seedling production, Shading.

\section{INTRODUÇÃO}

A flora do Cerrado com suas formas de hábito herbáceo a arbóreo possui grande variação fitofisionômica, apresentando formações florestais, savânicas e campestres de acordo com as modificações das características do solo de cada local (EITEN, 1972). Nos últimos anos, as espécies nativas do Cerrado, muitas vezes pouco conhecidas, estão ameaçadas a desaparecer. Este fato acontece em razão da destruição da biodiversidade, devido, principalmente, à expansão agropecuária, aos contaminantes ambientais, à erosão e à exploração de espécies de forma predatória (FERREIRA et al., 2009).

Áreas degradadas decorrentes de atividades de exploração perdem sua estrutura e função na natureza. Para recuperá-las ou reabilitá-las é necessário combinar o preparo do local com a introdução de espécies nativas, mas isso é um grande desafio para a ciência segundo FILGUEIRAS \& FAGG (2008). Ainda de acordo com autores, uma das formas de se tentar recuperar áreas degradadas é o plantio de espécies da camada subarbustiva, pois esta favorece uma melhor fixação do solo por meio de seu sistema subterrâneo de raízes, as quais ocupam, temporariamente, os espaços para criar condições de estabelecimento de outras formas de vida, como arbustos e árvores.

Nesse sentido, é possível recuperar o Cerrado utilizando técnicas de plantio que consistem principalmente em usar espécies nativas do local, respeitando-se as condições de umidade, fertilidade do solo, luminosidade, densidade da vegetação original, dando prioridade para espécies atrativas à fauna silvestre e controlando a entrada de espécies exóticas (DURIGAN et al., 2011). Além do crescimento natural de cada espécie vegetal, existem vários fatores ambientais que podem influenciar no desenvolvimento da espécie, desde propagação e produção de mudas em viveiros. Temperatura, nutrientes no solo, disponibilidade de água, luz e tamanho do recipiente, influenciam diretamente no desenvolvimento das plantas (SCALON et al., 2001).

Em resposta a diferentes intensidades de luz, as espécies vegetais tendem a realizar ajustes morfológicos, fisiológicos e alterações no desenvolvimento (ALMEIDA et al., 2005). Essas alterações das plantas em relação à disponibilidade de luz é uma resposta específica de cada espécie. Trabalhos conduzidos sob telados de sombrite mostram que existem espécies que se desenvolvem bem em diferentes níveis de disponibilidade de luz (DANTAS et al., 2009; PACHECO et al., 2013; FARIA et al., 2013b).

Algumas espécies são intolerantes à sombra, ou seja, desenvolvem-se melhor em ambientes com alta disponibilidade de luz (FERREIRA et al., 2012). Outras espécies toleram ou tem preferência por ambientes sombreados e suas plântulas são 
capazes de alcançar a maturidade em locais de dossel fechado (DUTRA et al., 2012; FERREIRA et al., 2012; LENHARD et al., 2013).

Segundo AUGSPURGER (1984), existe, naturalmente, uma amplitude de sobrevivência das plântulas na sombra representada por um contínuo de tolerância e não uma divisão entre as espécies tolerantes e as que não toleram. Outro fator que interfere na produção de mudas de qualidade é o tamanho do recipiente utilizado. Ele deve ter um tamanho que permita o desenvolvimento da parte aérea e também do sistema radicular sem restrições significativas, durante o período de permanência da muda no viveiro. O tamanho do recipiente tem influência direta no custo final da muda, principalmente na quantidade do substrato utilizado, no espaço ocupado no viveiro, na mão-de-obra utilizada e no processo de carregamento para o transporte (QUEIROZ \& MELÉM JÚNIOR, 2001).

Desta forma, objetivou-se investigar, o vigor das sementes e desenvolvimento inicial de espécies da camada rasteira do bioma Cerrado em condição de viveiro.

\section{MATERIAL E MÉTODOS}

Avaliaram-se as respostas fisiológicas de sementes de quatro espécies do estrato herbáceo e subarbustivo do Cerrado. Os frutos foram coletados em diversos locais e fitofisionomias, como apresentados no quadro 1.

QUADRO 1 - Espécies de estudo e respectivas fitosionomias de coleta no Cerrado

\begin{tabular}{|c|c|c|}
\hline Espécie & Fitofisionomia & Local de Coleta \\
\hline $\begin{array}{l}\text { Psychotria } \\
\text { trichophora Müll. Arg. }\end{array}$ & Floresta Estacional Semi-Decidual & $\begin{array}{c}\text { 1634'58.24"S e } \\
\text { 49917'31.20'O }\end{array}$ \\
\hline $\begin{array}{l}\text { Clidemia hirta (L.) D. } \\
\text { Don. }\end{array}$ & Mata Ciliar e Mata Estacional & $\begin{array}{l}1651 \text { '43.55"S e } \\
47919 ' 12.01 \text { "O }\end{array}$ \\
\hline Senna alata (L.) Roxb. & Áreas úmidas e brejosas & $\begin{array}{c}\text { 1635'35.02"S e } \\
4991517.10 " O\end{array}$ \\
\hline Olyra latifolia L. & Floresta Estacional Semi-Decidual & $\begin{array}{c}\text { 1729'33.33"S e } \\
5122 ' 59.68 " O\end{array}$ \\
\hline
\end{tabular}

\section{Vigor de sementes}

Para determinação do vigor das sementes foi empregado o teste de tetrazólio. Inicialmente, houve despolpamento de frutos para a extração de sementes e remoção de impurezas. As sementes foram mantidas em local seco para a retirada do excesso de umidade.

Para a execução do Teste de Tetrazólio, foram empregadas 10 sementes de cada espécie. As mesmas foram embaladas em papel de germinação umedecido e mantidas nessas condições por 24 horas em temperatura ambiente. Após esse précondicionamento e embebição, as sementes foram cortadas ao meio com uma lâmina, com finalidade de facilitar a reação dos sais de tetrazólio com o tecido vivo do material, permitindo a leitura da coloração posteriormente. Antes de serem levadas para a estufa em temperatura de $35^{\circ} \mathrm{C}$, as sementes foram colocadas em frascos de béquer e cobertas com uma solução de tetrazólio a $1 \%$, onde permaneceram por 3h30min (FRANÇA-NETO et al., 1998).

Após esses procedimentos, as sementes foram analisadas quanto à viabilidade do embrião com auxílio de um microscópio estereoscópio. As sementes 
que possuíam coloração rosa brilhante foram consideradas viáveis. Sementes que não apresentavam coloração rosa intensa ou branca foram consideradas não viáveis.

\section{Produção de mudas}

Realizou-se a semeadura das diferentes espécies em dois tipos de recipientes: bandejas de isopor $\left(50 \mathrm{~cm}^{3}\right.$ célula $\left.^{-1}\right)$ e sacos de polietileno $\left(138 \mathrm{~cm}^{3}\right.$ unidade $^{-1}$ e distribui-se uma semente por célula ou saco. Foi utilizado o substrato Qualifibra $^{\circledR}$ composto por casca de Pinus, esterco bovino, vermiculita, carvão vegetal, rocha calcária, superfosfato simples, nitrato de amônio, farelos e tortas de origem vegetal. Os ambientes de manutenção destas mudas consistiram em: pleno sol ou telado (50\% de sombra). Foram utilizadas cinco repetições com 25 plantas por parcela.

A emergência de plântulas foi avaliada semanalmente até 40 dias. A altura de plantas foi determinada aos oito, 23, 38, 53 e 68 dias após a emergência. $O$ diâmetro do coleto foi determinado somente aos 68 dias após a emergência. A caracterização de crescimento das mudas somente foi conduzida para S. alata. As demais não apresentaram emergência nem crescimento suficientes para tal determinação.

Foram utilizadas cinco plantas de cada repetição, retiradas de forma aleatória dos recipientes (sacos plásticos e células de bandejas de isopor) e, em seguida, tiveram suas raízes lavadas em água corrente. O material foi colocado para secar em estufa de ventilação forçada, a $60{ }^{\circ} \mathrm{C}$ por 58 horas. A massa de matéria seca radicular e de parte área foram determinadas por meio de gravimetria.

\section{Análises Estatísticas}

A significância do efeito das espécies na viabilidade de semente e de recipientes e ambientes na produção de mudas de $S$. alata foi determinada por meio do Teste $F$, sendo as médias comparadas por meio do Teste de Tukey $(p<0,05)$.

\section{RESULTADOS E DISCUSSÃO}

A partir do teste de tetrazólio, pode-se determinar a viabilidade do lote de sementes possibilitando a obtenção de resultados rápidos, gerando informações que permitem a identificação das causas de perda da viabilidade das sementes.

Sementes de $S$. alata e $P$. trichophora apresentaram $100 \%$ de viabilidade do embrião. Já a espécie $C$. hirta apresentou $90 \%$ de viabilidade do embrião. Foram observados apenas $10 \%$ de viabilidade do embrião de Olyra latifolia, uma vez que $90 \%$ das sementes estavam malformadas ou ocas no momento do corte, provavelmente por estarem imaturas, considerando que foram coletadas precocemente no campo, o que, certamente, refletiu nos baixos porcentuais de viabilidade e germinação.

Entre as quatro espécies estudadas, $P$. trichophora e $O$. latifolia não emergiram. C. hirta apresentou emergência inferior a $50 \%$ e $S$. alata sobressaiu em relação as demais espécies estudas (Figura 1). Uma das possíveis explicações para ausência de emergencia de $P$. trichophora é a ocorrência de dormência das sementes. Está espécie é dispersa por aves (MESQUITA-NETO et al., 2015), a 
alternância de temperaturas, escarificação e a passagem das sementes ou dos frutos pelo trato digestivo podem estimular a germinação em ambiente natural. Nesse experimento, nenhuma técnica foi utilizada para propiciar a superação de dormência das sementes. Foram observadas plantas de $O$. latifolia que apresentavam germinação de suas sementes ainda na panícula, esse evento corrobora com o baixo índice de aproveitamento das sementes usadas neste trabalho. Além dos aspectos já discutidos, várias espécies podem apresentar alta porcentagem de sementes estéreis ou com embriões pouco desenvolvidos, o que contribui para a lentidão e o baixo sucesso germinativo segundo CHAVES et al., (2011).

Devido às condições intrínsecas, as plântulas de $C$. hirta começaram a emergir somente a partir de 60 dias após a semeadura. Segundo FERREIRA et al., (1994), as sementes dessa espécie apresentam dormência primária relacionada ao tegumento. A emergência de C. hirta ocorreu somente no ambiente com $50 \%$ de sombra, o que confirma um padrão associado aos locais de ocorrência da espécie (Figura 1).

As plântulas $S$. alata emergiram na primeira semana após a semeadura. A determinação da caraterísticas morfológicas e massa seca (MS) foi realizada apenas com as plantas de Senna alata, pois as outras espécies não emergiram ou ainda não apresentavam tamanho suficiente para avaliação até o final do experimento.

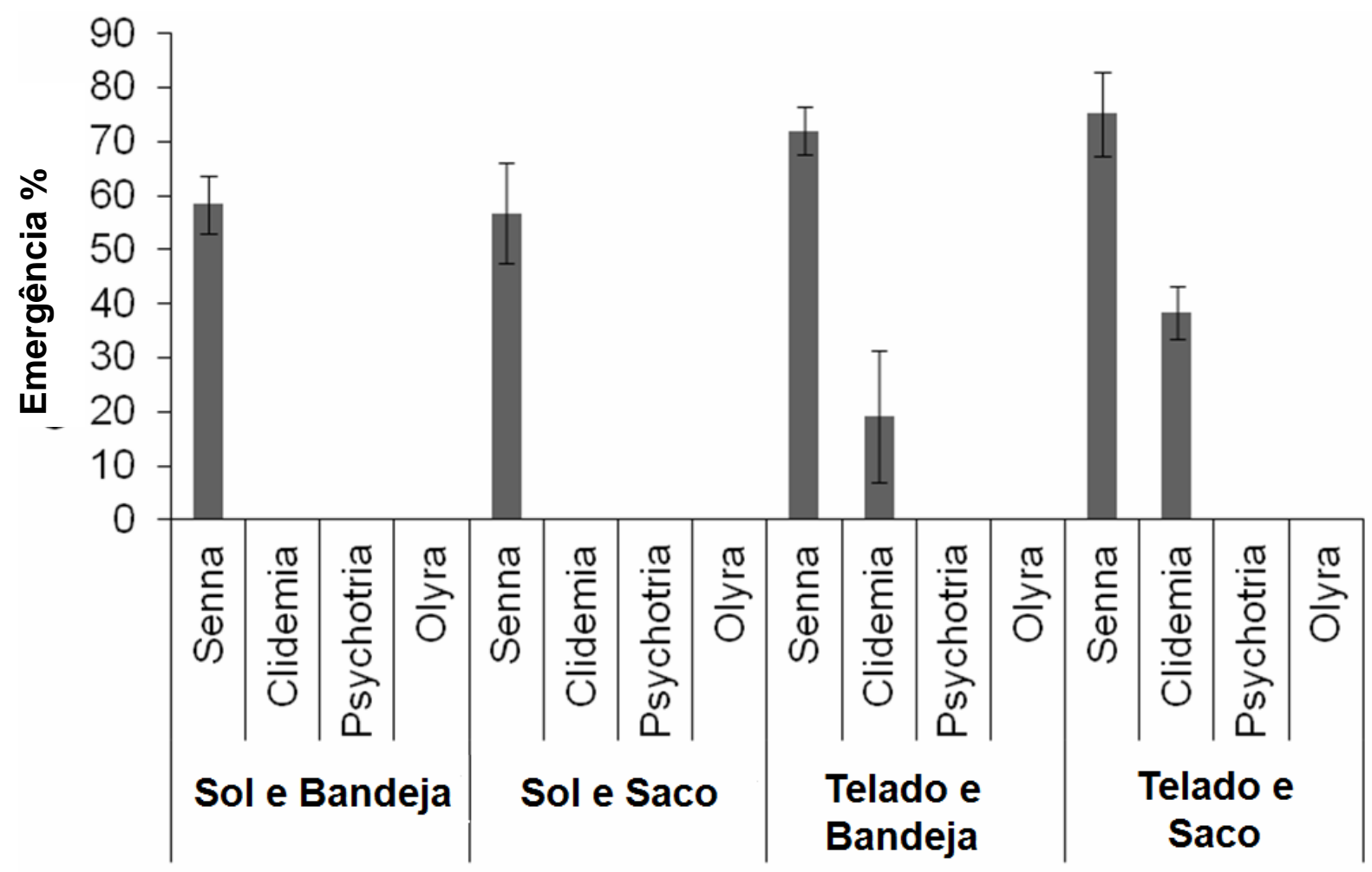

FIGURA 1. Emergência de plântulas de Senna, Clidemia, Psychotria e Olyra em função do tipo de recipiente e ambiente de manutenção das mudas.

Os resultados mostraram que a luz é um fator que influencia diferentemente as espécies do Cerrado, podendo produzir ou não efeitos sobre a germinação (LIMA 
et al., 2014). O ambiente do telado, com $50 \%$ de luz, conseguiu reter $23 \%$ da luz em relação ao ambiente a pleno sol. Essa perda da capacidade de retenção da luz no ambiente do telado (sombrite) é reflexo do tempo de uso do material.

As sementes de $S$. alata germinaram em condições de pleno sol e em ambiente sombreado e nos diferentes tipos de recipiente (Figura 1). Porém pode-se observar que a emergência foi superior nos tratamentos que receberam sombreamento. Visto que é uma espécie subarbustiva pioneira, mais rústica, tolerante ao sol pleno, e menos exigente. Ressalta-se que estas características são típicas de áreas degradadas e pastagens, ou seja, de áreas altamente expostas à radiação solar. Entretanto, essa espécie pode ser encontrada naturalmente em capoeiras e áreas alagadas ou de charco. O que confere a esta espécie uma estratégia de ocupação potencial de diferentes fisionomias de Cerrado (FARIA et al., 2013a). O tipo de recipiente não afetou a expressão desta emergência.

$\mathrm{Na}$ avaliação das características morfológicas das mudas de $S$. alata, observa-se que em todas as medições do crescimento em altura $(H)$, nas diferentes datas avaliadas, houve diferença significativa entre os ambientes, sombreado e a pleno sol e entre os tipos de recipientes, bandeja e saco plástico (Figura 2).

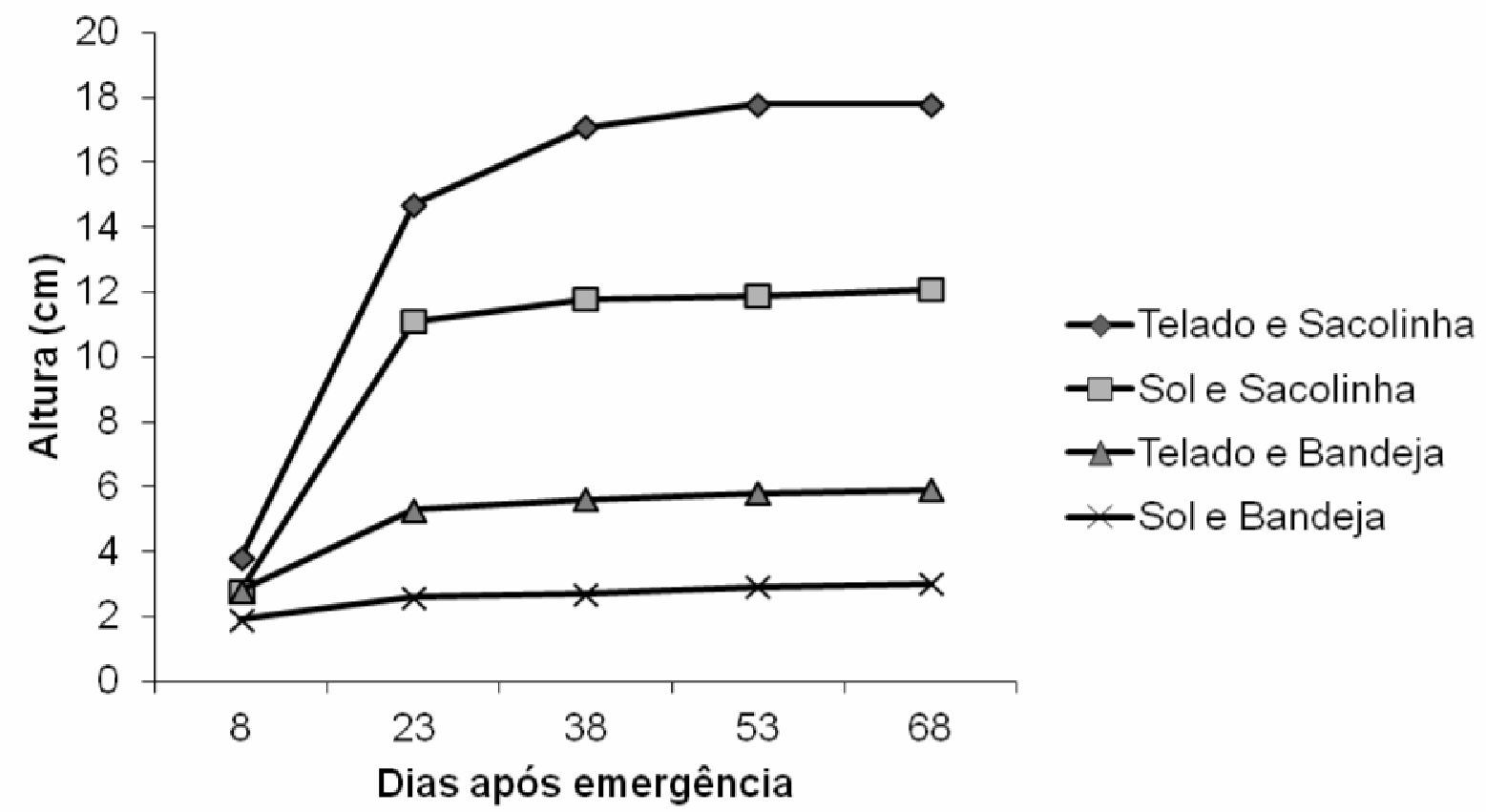

FIGURA 2. Comparação da altura das plantas de Senna alata em diferentes avaliações, recipientes e ambiente. (Interação de avaliação $\mathrm{x}$ recipiente $x$ ambiente $F(3,64)=1,2575 ; p=0,296) / \quad$ (Efeito isolado do fator recipiente, ambiente $p<0,05)$.

No ambiente sombreado e em recipiente saco plástico o crescimento em altura das mudas foi aproximadamente cinco centímetros maior em relação ao pleno sol, além de apresentar um ganho no diâmetro de coleto. Esses ganhos em relação a estas características representam redução no tempo de permanência das mudas no viveiro e minimização dos custos de produção. O tratamento a pleno sol e recipiente bandeja apresentaram os menores valores de crescimento. Apesar de $S$. alata ser uma espécie tolerante ao sol, seu melhor desempenho em ambiente 
sombreado pode estar relacionado à busca de luminosidade pelas plantas segundo MELO \& CUNHA (2008). De acordo com ALMEIDA et al. (2005), as espécies Hymenaea courbaril L., Maclura tinctora L., e S. alata, quando colocadas em diferentes níveis de sombreamento $(0 \%, 30 \%$ e $50 \%)$ demonstraram uma maior média na altura quando expostas a maior sombreamento.

O resultado encontrado no presente estudo também pode ser respondido pela definição de SMITH \& WHITELAM (1990). Segundo os autores, o aumento em altura nas plantas que se desenvolvem em áreas sombreadas é considerado uma resposta morfogênica típica. Ou seja, nessas condições, em geral, ocorre uma alocação rápida de assimilados para a parte aérea, o que permite à planta ultrapassar a vegetação ao seu redor e expor de maneira mais favorável à sua superfície fotossintetizante à luz.

Pode-se observar que o tipo de recipiente influencia de forma significativa o crescimento das plântulas (Figura 3). O saco plástico provavelmente por ser maior, disponibilizou mais nutrientes e água para as plântulas, além de não limitar o crescimento das raízes. Para BÖHM (1979), as dimensões dos recipientes e os consequentes volumes influenciam a disponibilidade de nutrientes e água. GUIMARÃES et al. (2015) verificaram que estresse hídrico em Handroanthus avellanedae (Lorentz ex Griseb.) Mattos durante a germinação das sementes e crescimento inicial provoca alterações no desenvolvimento da espécie.

De acordo com os resultados de massa de matéria seca da parte aérea e radicular, constata-se que houve diferença entre os recipientes, saco plástico e bandeja, porém entre os ambientes não ocorreu diferença significativa, entretanto em ambiente sombreado proporcionou um maior acumulo de massa seca (Figura 3). CARVALHO-FILHO et al. (2002) estudaram o desenvolvimento de mudas de Cassia grandis L. em pleno sol e ambiente sombreado e observaram que as plantas sombreadas apresentaram maior número de folhas, altura, diâmetro de caule e massa de matéria seca de parte aérea em relação às que estavam a pleno sol.

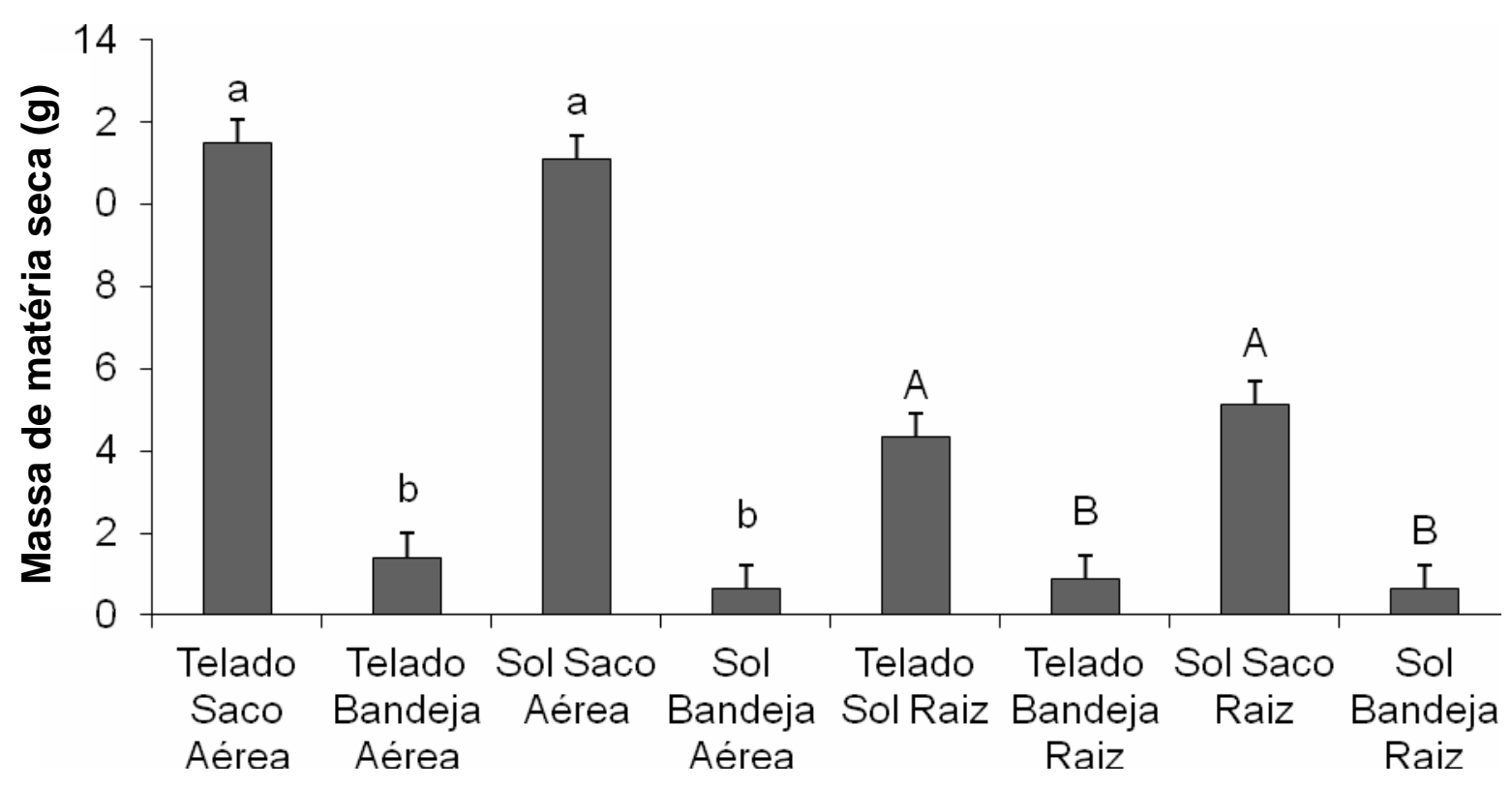

FIGURA 3. Massa de matéria seca de mudas de $S$. alata produzidas em diferentes recipientes e ambientes. Letras diferentes, maiúsculas e minúsculas 
indicam diferença estatística entre tratamentos de parte aérea e raiz, respectivamente.

Repetiu-se mesmo padrão de distribuição de massa de matéria seca para a parte radicular, não sendo observadas diferenças entre os ambientes e apresentando diferença entre os recipientes. Entretanto, houve um maior acumulo de massa de matéria seca de plântulas no recipiente saco plástico a pleno sol. Esse maior crescimento de raiz permite uma maior absorção de água e nutrientes, estratégia que garante a planta capacidade de suportar taxas mais elevadas de fotossíntese e transpiração em ambientes mais iluminados. Segundo MOTA et al. (2013), ocorre uma redução do crescimento da parte aérea e um aumento do crescimento radicular para que a planta consiga absorver água nas camadas mais profundas do solo e diminuir a perda de água pelas folhas. SILVA et al. (2007), relatam que plantas de Hymenaea parvifolia Huber. sob maior intensidade luminosa apresentam um maior acúmulo de massa seca na raiz.

\section{CONCLUSÃO}

As sementes de Clidemia hirta e Psychotria trichophora devem ser tratadas para que ocorra a superação da dormência relacionada ao tegumento, para acelerar e homogeneizar a germinação e emergência.

O recipiente saco plástico proporcionou um melhor desenvolvimento das mudas de $S$. alata. A espécie $S$. alata, mesmo sendo mais tolerante à luz, se desenvolve melhor em ambiente de telado com $50 \%$ de luz.

\section{REFERÊNCIAS}

ALMEIDA, S. M. Z.; SOARES, A. M.; CASTRO, E. M.; VIEIRA, C. V.; GAJEGO, E. B. Alterações morfológicas e alocação de biomassa em plantas jovens de espécies florestais sob diferentes condições de sombreamento. Ciência Rural, v. 35, n. 1, p. 62-68, 2005.

AUGSPURGER, C. K. Light requirements of neotropical tree seedling: A comparative study of growth and survival. Journal of Ecology, v. 72, n. 3, p. 777-795, 1984.

BÖHM, W. Methods of studying root systems. SpringerVeriag, Berlin, 188 p.,1979.

CARVALHO FILHO, J. L. S.; BLANK, M. F. A.; BLANK, A. F.; SANTOS NETO, A. L.; AMÂNCIO, V. F. Produção de mudas de Cassia grandis L. em diferentes ambientes, recipientes e misturas de substratos. Revista Ceres, v. 49, n. 84, p. 341-352, 2002.

CHAVES, I. S.; ALVARENGA, A. A.; DOUSSEAU, S.; SOARES, G. C. M. S.; SOUZA, E. S. S.; ARTUR, M. A. S. Germination of Miconia ligustroides (Melastomataceae) diaspores submitted to different treatments for dormancy overcoming. Revista Brasileira de Botânica, v. 34, n. 3, p. 335-341, 2011.

DANTAS, B. F.; LOPES, A. P.; SILVA, F.F.S.S.; LÚCIO, A. A.; BATISTA, P.F.; PIRES, M. M. M. L.; CARLOS, A. A. Taxas de crescimento de mudas de catingueira submetidas a diferentes substratos e sombreamentos. Revista Árvore, v. 33, n. 3, p. 413-423, 2009. 
DURIGAN, G.; MELO, A. C. G.; MAX, J. C. M.; BOAS, O. V.; CONTIERI, W. A.; RAMOS, V. S. Manual para Recuperação da Vegetação de Cerrado. 3 ed. São Paulo: Páginas \& Letras Editora e Gráfica, 2011.

DUTRA, T. R.; GRAZZIOTTI, P. H.; SANTANA, R. C.; MASSAD, M. D. Desenvolvimento inicial de mudas de copaíba sob diferentes níveis de sombreamento e substratos. Revista Ciência Agronômica, v. 43, n. 2, p. 321-329, 2012.

EITEN, G. The Cerrado vegetation of Brazil. The Botanical Review, v. 38, p. 201$341,1972$.

FARIA, R. A. P. G.; ALBUQUeRQUE, M. C. F.; COELHO, M. F. B. Tamanho da semente e sombreamento no desenvolvimento inicial de Brosimum gaudichaudii TRÉCUL. Revista Caatinga, Mossoró, RN, v. 26, n. 1, p. 09-15, $2013 a$.

FARIA, J. C. T.; WINCKLER, M. V.; DELARMELINA, W. M. C.; ROCHA, R. L. F. Uso de resíduos orgânicos na produção de mudas de Senna alata (L.) Roxb. Ecologia e Nutrição Florestal, Santa Maria, RS, v. 1, n.3, p.133-146, $2013 \mathrm{~b}$.

FERREIRA, W. N.; ZANDAVALLI, R. B.; BEZERRA, A. M. E.; MEDEIROS, F. S. Crescimento inicial de Piptadenia stipulacea (Benth.) Ducke e Anadenanthera colubrina (Vell.) Brenan var. sob diferentes níveis de sombreamento. Acta Botanica Brasilica, Belo Horizonte, MG, v. 26, n. 2, p. 408-414, 2012.

FERREIRA, L. G.; FERREIRA, M. E.; ROCHA, G. F.; NEMAYER, M.; FERREIRA, N. C. Dinâmica agrícola e desmatamentos em áreas de Cerrado: uma analise a partir de dados censitários e imagens de resolução moderada. Revista Brasileira de Cartografia, v. 02, n. 61, p.117-127, 2009.

FERREIRA, S. A. N.; COHEN, I. A.; JANSEN, M. R. Biologia Reprodutiva de Clidemia hirta (L.) D. Don (Melastomataceae). Acta Amazônica, v. 4 n. 24 p. 183188,1994 .

FILGUEIRAS, T. S.; FAGG, C. W. Gramíneas nativas para recuperação de áreas degradadas no cerrado. In: FELFILI, J. M.; SAMPAIO, J. C.; CORREIA, C. R. M. A. Org(s). Bases para a Recuperação de Áreas Degradadas na Bacia do São Francisco. Brasília-Centro de Referência em Conservação da Natureza e Recuperação de Áreas Degradadas (CRAD). p. 216, 2008.

FRANÇA NETO, J. B.; KRZYZANOWSKI, F. C.; COSTA, N. P. O teste de tetrazólio em sementes de soja. EMBRAPA-CNPSo. Documentos, v. 116, p. 72, 1998.

GUIMARÃES, L. E.; CHAVES FILHO, J. T.; SILVA NETO, C. M.; OLIVEIRA, F. D. Estresse hídrico na germinação e desenvolvimento inicial de Handroanthus avellanedae (Lorentz ex Griseb.) Mattos em ambiente protegido. Enciclopédia Biosfera, v. 11, p. 997-1005, 2015.

LENHARD, N. R.; PAIVA NETO, V. B.; SCALON, S. P. Q.; ALARENGA, A. A. Crescimento de mudas de pau-ferro sob diferentes níveis de sombreamento. Pesquisa Agropecuária Tropical, v. 43, n. 2, p. 178-186, 2013. 
LIMA, Y. B. C.; DURIGAN, G.; SOUZA, F. M. B. Germinação de 15 espécies vegetais do cerrado sob diferentes condições de luz. Bioscience Journal, v. 30, n. 6, p.937-948,2014.

MELO, R. R.; CUNHA, M. C. L. Crescimento inicial de mudas de mulungu (Erythrina velutina Wild.) sob diferentes níveis de luminosidade. Ambiência, v. 4, n. 1, p. 67$77,2008$.

MESQUITA-NETO, J. N.; SILVA-NETO, C. M.; FRANCESCHINELLI, E. V. Theoretical predictions of plant-pollinator interactions in sympatric species of Psychotria (Rubiaceae) in Cerrado of Brazil. Plant Ecology and Evolution, v. 2, n.148, p. 229-236, 2015.

MOTA, L. H. S.; SCALON, S. P. Q.; MUSSURY, R. M. Efeito do condicionamento osmótico e sombreamento na germinação e no crescimento inicial das mudas de angico (Anadenanthera falcata Benth. Speg.). Revista Brasileira Plantas Medicinais, v. 15, n.4, p.655-663, 2013.

PACHECO, F. V.; PEREIRA, C. R.; SILVA, R. L.; ALVARENGA, I. C. A. Crescimento inicial de Dalbergia nigra (Vell.) Allemão ex. Benth. (Fabaceae) e Chorisia speciosa A.St.-Hil (Malvaceae) sob diferentes níveis de sombreamento. Revista Árvore, v. 37, n. 5, p. 945-953, 2013.

QUEIROZ, J. A.; MELÉM JÚNIOR, N. J. Efeito do tamanho do recipiente sobre o desenvolvimento de mudas de açaí (Euterpe olaracea Mart.). Revista Brasileira de Fruticultura, v. 21, n. 1, p. 460-462, 2001.

SCALON, S. P. Q.; SCALON FILHO, H.; RIGONI, M. R.; VERALDO, F. Germinação e crescimento de mudas de pitangueira (Eugenia uniflora L.) sob condições de sombreamento. Revista Brasileira de Fruticultura, v. 23, n. 3, p. 652-655, 2001.

SMITH, H.; WHITELAM, G. C. Phytochrome. A family of photoreceptors with ultiple physiological roles. Plant Cell Environment, v. 1, n. 13, p. 695-707, 1990.

SILVA, B. M. S.; LIMA, J. D.; DANTA, V. A. V.; MORAES, W. S.; SABONARO, D.Z. Efeito da luz no crescimento de mudas de Hymenaea parvifolia Huber. Revista Árvore, v. 6, n. 31, p. 1019-1026, 2007. 